\title{
VIOLÊNCIA CONTRA A MULHER DECORRENTE DO MACHISMO: UM FATO SOCIAL DE BASE CRISTÃ
}

\author{
Líbia Kícila Goulart ${ }^{1}$ \\ Dulce Helena Pontes-Ribeiro ${ }^{2}$
}

RESUMO: Este ensaio argumenta a tese de que grande parte de casos de violência contra a mulher ocorrem devido ao machismo impregnado na sociedade desde o surgimento do cristianismo e que, por ocasião da pandemia da Covid-ı́, os índices de feminicídio têm aumentado. Para fundamentação teórico-metodológica recorreu-se aos clássicos da Sociologia: Marx, Durkheim e Weber - a partir dos quais se estabelece uma conversa sociológica para entender os casos mais recentes desse fato social.

Palavra-chave: Violência. Mulher. Machismo. Igreja.

ABSTRACT: This essay argues the thesis that most cases of violence against women occur due to the machismo impregnated in society since the rise of Christianity and that, due to the Covid-ig pandemic, the rates of femicide have increased. For theoretical-methodological foundation, we resorted to the classics of Sociology: Marx, Durkheim and Weber - from which a sociological conversation is established to understand the most recent cases of this social fact.

Keyword: Violence. Woman. Chauvinism. Church.

\section{INTRODUÇÃO}

O presente texto, caracterizado como ensaio, expõe determinado ponto de vista, isto é, certo ângulo de compreensão sobre o tema da violência contra a mulher (nosso objeto de discussão sociológica), obviamente sem o intento de exaurir a questão. Parte-se da tese de que o machismo - cujas origens se encontram nas fontes do cristianismo quando as diferenças entre os gêneros eram bem delimitadas (o homem o cabeça da família, a mulher

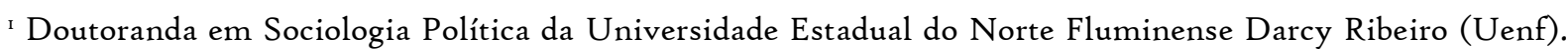
Mestre em Ciências das Religiões (Unidas de Vitória/ES). Especialista em Processo Civil (PUC/MG). Graduada em Direito (Universidade Iguaçu, campus V) e em Serviço Social (UFF). Atua como advogada e também como professora do Centro Universitário UniRedentor/Afya (Itaperuna/RJ). E-mail: libiakicila@hotmail.com.

${ }^{2}$ Doutora em Língua Portuguesa (Uerj). Mestra em Educação (UCP). Especialista em Língua Portuguesa (Fafita) e em Semiótica Discursiva (Uniara). Graduada em Letras (Fafita). Professora do Ensino Superior (Centro Universitário São José). Revisora de textos científicos, acadêmicos, TCC, livros, etc. E-mail: dulcehpontes@gmail.com.
} 
a rainha do lar) - tem sido a maior causa da violência contra a mulher e, mais especificamente, hoje, quando vivenciamos as agruras decorrentes das imposições de isolamento social com o advento da pandemia da Covid-ı.

Em face dos avanços científico-tecnológicos e democráticos, os atos de violência, em especial contra as mulheres, parecem incoerentes. Assim, buscamos nos clássicos da Sociologia (Karl Marx, Émile Durkheim e Max Weber) fundamentações teóricometodológicas para a construção de nossa concepção sociológica. Procuramos entender com Marx (I8I8-1883), acima de qualquer outro respaldo, que os "homens de carne e osso" agem conforme suas carências materiais no curso da História. Sua dialética de perspectiva histórica articulada ao materialismo, à posse, à propriedade privada nos leva a entender que os sentidos físicos e espirituais cedem lugar ao capital, ao ato de possessão.

Em Durkheim (1858-1917), encontramos a diretriz para o trabalho do sociólogo: em vez de meditações metafísicas, tomamos como propósito e análise as coisas sociais, onde elas (de modo delimitado) começam e terminam. Aprendemos que não são as generalizações sociológicas que atenuam as causas de mal-estar da sociedade, nem mesmo são capazes de elucidá-las teoricamente. Com o método de Durkheim, verificamos que é necessário que o estudo de determinada causa envolva suas manifestações.

A despeito das críticas ao monismo causal que tipifica o materialismo marxista em formas vulgares, Weber (1864-1920), refinando tais ideias, nos possibilitou analisar e explicar a história social pelo materialismo histórico, compreendendo os eventos culturais como singularidades. E, em face de uma realidade cultural infinita, procuramos o foco no estudo da especificidade do fenômeno, isto é, delimitá-lo num fragmento ínfimo, porém relevante.

Banhados nessa linha de intelecção, objetivamos neste ensaio explicar o crescente índice de violência contra a mulher - muitas vezes culminando em feminicídios -, mais especificamente nestes tempos pandêmicos em que o planeta entra em colapso não somente na questão da saúde pública, mas também inexoravelmente no quesito economia mundial, perturbando sobremaneira a convivência social. Para este intento, num primeiro momento, procuramos costurar, naquilo que é possível, as concepções sociológicas de Marx, Durkheim e Weber; depois buscamos relação entre o machismo (as violências dele decorrentes) e a questão religiosa; por fim, trazendo para a contemporaneidade o aumento de feminicídios 
ocorridos por ocasião da pandemia do novo coronavírus a partir de notícias recentes, estabelecemos uma conversa entre o aporte teórico-metodológico desses clássicos com o nosso objeto de estudo.

\section{UMA CONFABULAÇÃO SOCIOLÓGICA ENTRE MARX, DURKHEIM E WEBER}

O clássico tripé da Sociologia contribui sobremodo para melhor compreendermos os fatos sociais e chegarmos a presumíveis interpretações ideológicas que impactam a realidade, como a permanência da violência contra a mulher resultante do machismo. Distintamente, Marx desenvolve a sociologia revolucionária, com o método materialista histórico-dialético e lutas de classe como objeto de estudo. Durkheim apoiando-se da linha positivista de Comte, cria o método funcionalista para entender o todo a partir do entendimento das funções de cada indivíduo na sociedade e toma os fatos sociais como objeto de estudo. Em vez de fatos sociais, Weber com a sociologia compreensiva procura compreender a sociedade pela função das ações sociais individuais, sendo estas, portanto, seu objeto de estudo.

Não coube a Marx o desenvolvimento de um trabalho de campo para o entendimento profundo e rigoroso da sociedade em todos os seus complexos vieses, mas sim a Durkheim, o pioneiro especialista empírico com o fim de compreender as estruturas sociais e, além disso, o sociólogo elevou a sociologia a níveis acadêmicos em cursos superiores. Já Weber, numa outra direção, para conferir rigor científico, inovou a sociologia criando tipos ideais, isto é, padrões esperados de comportamento social para entender a sociedade.

Distinto do idealismo da filosofia alemã, Marx procurou compreender os homens em suas necessidades reais - bases da explicação da vida social do homem como ser transformador da sociedade a partir de seu trabalho, originando-se daí discussões sobre desigualdades sociais vinculadas a processos histórico-sociais. Pelo seu método de abordar a vida social, política, econômica e intelectual (cunhado mais tarde de materialismo históricodialético), entendemos que, quanto mais se valorizam as coisas materiais e a posse delas como capital mais se desvalorizam as humanas e espirituais, e mais estúpidos se tornam os homens. Para além da geração de coisas, segundo o materialismo histórico, estão as ideologias em suas esferas múltiplas (religiosa, política, moral, estética, legal, filosófica, 
científica, educacional comunicativa, dentre outras) e no modo de as representar, comunicar, sentir, conceber e pensar.

Já o método de Durkheim considera, no fato social investigado, todas as suas manifestações particulares para então compará-las e delas extrair as características comuns. Parte-se das mais aparentes até se chegar às menos visíveis, que são mais profundas. Praticase aí o método indutivo para, enfim, atingir as generalizações e elaboração dos conceitos científicos, de modo que o essencial (que é o geral e comum) está nos fenômenos repetidos, constantes e permanentes; qualquer diferença/alteração é secundária. A origem dos fenômenos sociais não está no indivíduo, mas na coletividade, nas formas específicas de pensamento desse todo de modo que cada indivíduo a elas se sujeita. Pelas representações coletivas se compreendem os modos de a sociedade se perceber e perceber o mundo em seu entorno, por exemplo: crenças, concepções religiosas, lendas, ideais e as próprias coisas de que faz uso.

Enquanto Durkheim compreende a sociedade a partir dos fatos sociais, Weber, em discordância veemente dessa teoria, compreende seu funcionamento pelas ações sociais praticadas pelos indivíduos. O trabalho, produzido e reproduzido pela força humana, constitui a história dos homens, e o resultado dele é acumulado e transmitido pela cultura; portanto, as forças produtivas não se constituem por livre arbítrio do homem, pois sua base é histórica, adquirida de ações/energias práticas antecedentes, condicionadas por um fio condutor social que lhe serve de matéria-prima para a renovação, o desenvolvimento e a humanização da natureza e do próprio homem. Na configuração dessa história, a função do homem é de mero animador.

Enfim, o perfil da Sociologia moderna como conhecimento científico com métodos e objeto específicos se delineou a partir mormente dos estudos de Marx, Durkheim e Weber.

\section{RELAÇÃO ENTRE MACHISMO (GERME DE BASE CRISTÃ) E VIOLÊNCIA CONTRA A MULHER}

Durkheim, em sua teoria funcionalista, vê a religião como força integrativa capaz de influenciar crenças coletivas, atribuir significado e finalidade à vida, prover o indivíduo do sentimento de pertencimento ao coletivo, revigorar a harmonização e o equilíbrio social, atuar como propulsor de controle social, fomentar o bem-estar físico e psicológico e encorajar 
o indivíduo a lutar por mudanças sociais. Mas, dando seguimento ao Catecismo de Comte, Durkheim mostrou a necessidade de uma moral forte de amparo à vida social, distinta da cristã, isenta de religiosidade e fé. Já para Weber a religião propicia apoio cultural instigador da prosperidade de demais instituições sociais como, por exemplo, a economia. Numa outra perspectiva, Marx concebe a religião como promotora de conflitos e opressões sociais. Ele a criticou cunhando-a de "o ópio do povo", utilizada por dominadores para sustentar suas ideologias e alienar o dominado da realidade.

O discurso religioso cristão sustenta a subordinação da mulher e sua dominação pelo homem para além de uma ação individual, mas como uma tradição instituída nos costumes. Inclusive, no Antigo Testamento, a mulher adúltera era apedrejada em praça pública, mas nada se diz no texto bíblico do homem adúltero. A vítima é transformada em culpada em defesa da honra do macho. Interpretamos aí um machismo disfarçado de moralidade, a nítida inferioridade da mulher, que nada mais é do que uma figurante, vinda ao mundo para completar uma carência do homem, sendo uma "coisa" criada para esse fim. Mas ela rompeu uma ordem do Paraíso abrindo a porta para o pecado e vem pagando por isso. A propósito, em carta, Paulo diz assim a I Timóteo (2: II a I5) sobre a ordenação de um culto:

A mulher aprenda em silêncio, com toda a sujeição. não permito, porém, que a mulher ensine, nem use de autoridade sobre o marido, mas que esteja em silêncio. porque primeiro foi formado adão, depois eva.e adão não foi enganado, mas a mulher, sendo enganada, caiu em transgressão. salvar-se-á, porém, dando à luz filhos, se permanecer com modéstia na fé, no amor e na santificação.

Compreendemos, então, que a força da religião sustentou a violência contra a mulher como uma construção histórica, como tantas outras. Neste caso, porém, tal força é relativa a papéis de gênero a serem seguidos numa determinada lógica da sociedade patriarcal, que, no curso do tempo, foram determinando o que compete ao homem e o que cabe à mulher na sociedade. Assim, discursos e práticas religiosas mais tradicionais de base cristã, em vez de contribuírem para dirimir o problema, reforçam-no na medida em que o casamento é concebido como uma união indissolúvel, segundo os planos de Deus; e a família é o lugar onde, a todo custo, seus membros devem manter os laços com dignidade e onde, por certo, germinou o machismo, que criou raízes profundas e se disseminou no seio familiar, escolar e laboral de tal modo que é muitas vezes imperceptível, normal, legal. 
A violência contra a mulher encontrou terreno favorável de intensificação e disseminação, também, no modo de produção capitalista, em que se verifica a desigualdade na relação de poder entre os gêneros: mulheres discriminadas moral e sexualmente e com salário inferior ao dos homens; mulheres no duplo papel de mães e trabalhadoras, tendo ora que abdicar de seus filhos deixando-os a cuidados de outrem, ora de seu trabalho remunerado para viverem sustentadas pelo parceiro. Apesar de Marx não abordar a questão do gênero, suas concepções teóricas contribuem substancialmente para tal abordagem.

Por meio do conceito durkheimiano de fato social, entendemos a violência contra a mulher fixada no bojo da hegemonia masculina como uma maneira de agir social. Esse fato social contém as características coercitividade (uma força imperativa agindo sobre o gênero feminino; o machismo é coercitivo), exterioridade (ação e pensamentos impostos pelo exterior) e generalidade (fenômeno próprio de uma coletividade). E assim entendemos o machismo como um fato social articulado a religiões cristãs ("Mulheres, sujeite-se cada uma a seu marido, como ao Senhor”, Efésios 5:22-23), mas a elas não se limita.

Já pela ótica de Weber, a dominação tem sua sustentação em bases jurídicas das quais se fundamenta sua legitimidade. Nesse sentido, o Código Civil que vigorou de 2016 a 2002 considerava o homem como chefe de família e a mulher, relativamente incapaz. Daí emergiu, até a década de 1970, a tese da legítima defesa da honra, que inocentava o homem de atos de violências contra a mulher, inclusive do feminicídio. Tal concepção ficou marcada com o clássico caso ocorrido em 1976 pelo playboy Doca Street sobre Ângela Diniz: o feminicídio em defesa da honra do macho. E até a década de I980 ainda se discutia se haveria crime em caso de estupro contra a esposa, já que a esta não cabia recusar a relação social.

Concebemos que o tipo de dominação patriarcal é resultante de uma dominação tradicional em que se obedece ao outro o que está estabelecido por tradição, uma fidelidade ensinada no núcleo familiar e reconhecidamente válida. Mas isso não basta para compreendermos o comportamento coletivo. Recorremos a Weber para então inferirmos que as ações dos indivíduos decorrem, em grande parte, da repetição de ações de outros indivíduos - uma estrutura, complementada com ideias e sentimentos coletivos, de difícil transformação para o indivíduo que, mergulhado nela, é, consoante pensamento 
durkheimiano, incapaz de alterá-la a seu bel prazer. Por essa trilogia sociológica, vamos direto ao ponto onde os conflitos acontecem.

\section{CASOS RECENTES DE VIOLÊNCIA CONTRA A MULHER POSTOS À LUZ DOS CLÁSSICOS DA SOCIOLOGIA}

Detivemo-nos aqui à reflexão de apenas poucos casos pinçados das principais manchetes envolvendo a violência contra mulheres, ocorridos no mês de junho de 202I, coincidentemente quando o dia Io fora definido para o lançamento da Campanha de Combate ao Feminicídio. Mais que justo diante do quadro de 1.338 mortes de mulheres no Brasil vitimadas por violência na pandemia, quando, inversamente, caem os casos de homicídios e latrocínios. Nesse sentido, Durkheim aponta a diretriz para o trabalho do sociólogo: em vez de se deter em meditações metafísicas, tome-se como propósito e análise as coisas sociais, onde elas começam e terminam, isto é, de modo delimitado, entretanto interligando história, etnografia e estatística - disciplinas indispensáveis a análises sociológicas. Assim, não são as generalizações sociológicas que atenuam as causas de malestar da sociedade, nem mesmo são capazes de elucidá-las teoricamente. É, sim, necessário, no método durkheimiano, o estudo de determinada causa com suas manifestações.

Presenciamos a olhos vistos que as medidas impostas de isolamento social em decorrência da pandemia da Covid-ı́ têm resultado num alto índice de violência contra a mulher no ambiente doméstico onde precisam conviver todos os membros da família dias e noites intermitentes. A convivência com agressores em períodos prolongados fez aumentar consideravelmente esse tipo de violência se comparado com o período pré-pandêmico. O que mais preocupa nesse contexto é a não correlação com o número de denúncias; afinal, a proximidade diuturna com o agressor dificulta a delação e impõe a regra do silêncio e da sujeição a que já nos referimos em I Timóteo (2: II a I5).

Pesquisas detectam que as vítimas de violência contra a mulher incidem mais sobre mulheres negras e de classe mais baixa. Há menos casos de denúncia nas classes altas, provavelmente para evitar a exposição pública. Vemos, então, publicados muito mais casos de feminicídios entre aquelas que perderam emprego e renda durante a pandemia. Dos meios de produção e das consequentes propriedades privadas vem a crítica marxista envolvendo, de um lado, exploração de classes, desumanização e poder delimitado a alguns e, de outro, 
restrição de liberdade e alienação para a grande maioria. Fragilizadas ou mesmo aniquiladas em sua fonte que lhe dava algum poder, a mulher ainda perde o seu direito fundamental de vida, a sua condição humana. Há casos também de violência contra a mulher culminada em feminicídio por muitos motivos. Exemplo disso, foi o assassinato de uma jovem estudante técnica de enfermagem (22 anos), a facadas, por um colega de turma pelo simples fato de um amor não correspondido. O caso ocorreu na praça de alimentação do Shopping Plaza em Niterói/RJ no dia 02 de junho de 2021. Simplesmente, o homem, detentor de poder sobre a mulher numa sociedade machista, não sabe ouvir um não. Casos como esse não são raros e não ocorrem apenas no ambiente de trabalho, mas em outros círculos e classes sociais.

Planaltina (Brasília/DF) registrou a morte de Leidenaura (35 anos), também a facadas, dentro de casa, no dia o6, pelo seu ex-companheiro. Ela já sofrera agressões anteriores quando moravam juntos - um fenômeno repetido, constante e permanente configurando-se num fato social, segundo Durkheim. Valdemir Pereira, o ex-, enxergou na violência o modo de resolver conflitos, de domesticar o domesticado, no entendimento de Weber.

Outra mulher, Fernanda Almeida (33 anos), é morta pelo esposo (a facadas!) dentro de casa também, no dia o8, em Sobradinho II (Brasília/DF). Motivo: discussões por ciúmes. A violência, "parteira de uma sociedade velha", como diria Marx, ainda se reproduz em profusão na sociedade atual. Os ensinamentos marxianos (apesar da cegueira em relação a gêneros) apontam caminhos para menos teorização e mais transformação. É disso que a sociedade contemporânea carece.

No dia 06, em São João de Meriti (Baixada Fluminense), a jovem Thaís (22 anos) foi baleada pelo namorado num baile. Motivo: ciúmes (também!). Um dos tiros pegou na cabeça. A vítima sobreviveu mesmo sofrendo duas paradas cardíacas, passando por cirurgia, tendo perdido sangue e massa encefálica que poderão (ou não) deixar sequelas. Pensando com Durkheim, os laços que deveriam unir os membros afetivos entre si, nestes casos, são como os que unem um ditador a seu subserviente, ou ainda, os de um proprietário a suas posses. E, nessas conjunturas, a mulher pertence ao homem.

Podemos parar por aqui, já que não foi nossa pretensão fazer um rastreamento dos casos, apenas trazer um mínimo deles à tona (porém relevante) para entender que a violência 
contra a mulher (muitas das quais culminada em feminicídio) não é por acaso, não é fato isolado; é fato social, emerge de um contexto marcado por uma ordem hierárquica desigual, cujas relações de gênero são permeadas de violência que, por serem cotidianas, são socialmente legitimadas, normalizadas e banalizadas e que, com a situação de pandemia, o fato social tomou mais corpo. Entendemos com Durkheim que, quanto menor o ambiente habitado por um grupo de pessoas, há mais probabilidade para a expansão das dessemelhanças, do ego, da personalidade autônoma.

Vemos nesses casos abordados que a nossa tradição está alicerçada na supremacia masculina sobre a feminina, na sua legitimidade moral de resolver conflitos por essa perspectiva - fruto, portanto, do discurso religioso (talvez mal interpretado) que assim modela os gêneros: "Mulheres, sujeite-se cada uma a seu marido, como ao Senhor, pois o marido é o cabeça da mulher, como também Cristo é o cabeça da igreja, que é o seu corpo, do qual ele é o Salvador. Assim como a igreja está sujeita a Cristo, também as mulheres estejam em tudo sujeitas a seus maridos" (Efésios 5:22-24).

\section{CONCLUSÃO}

Nessa linha de intelecção, objetivamos neste ensaio explicar o crescente índice de violência doméstica - muitas das quais culminando em feminicídios -, mais especificamente nestes tempos pandêmicos em que o planeta entra em colapso não somente na questão da saúde públicas, mas também inexoravelmente no quesito economia mundial. Para este intento, num primeiro momento, procuramos costurar, naquilo que nos foi possível, as concepções de Marx, Durkheim e Weber; depois, relacionamos machismo (e as violências dele decorrentes) com a questão religiosa; por fim, trazendo para a contemporaneidade, pontuamos o aumento de feminicídios ocorridos por ocasião da pandemia do novo coronavírus, a partir de alguns exemplos ocorridos em junho deste ano (202I) e tendo como aporte teórico as concepções sociológicas desses referidos clássicos.

A despeito de mudanças intensas e radicais do modo de vida da humanidade, nos mais distintos setores da vida em sociedade, o terceiro milênio ainda é palco de práticas variadas de violência doméstica - razão pela qual se fazem indispensáveis reflexões críticas acerca desta temática que, neste ensaio, fora tomada como objeto de discussão. Para Marx, 
a razão seria o caminho para entender a realidade e tornar a vida social mais justa. Por isso, buscamos na Sociologia, explicações articulando teoria e casos concretos e constatamos que seu legado é ainda eficaz para produções sociológicas contemporâneas.

\section{BIBLIOGRAFIA}

BÍBliA, A. T. Sagrada Bíblia Católica: Antigo e Novo Testamentos. Trad.: José Simão. São Paulo: Sociedade Bíblica de Aparecida, 2008.

QUINTANEIRO, T.; BARBOSA, M. L. O.; OLIVEIRA, M. G. Um toque de clássicos: Marx, Durkheim e Weber. 2. ed. Belo Horizonte: UFMG, 2002. 